\title{
Numerical investigation on the performance of bluff body augmented micro cavity-combustor
}

\author{
Zheng Zhang ${ }^{a, d}$, Kun $\mathrm{Wu}^{b}$, Richard Yuen ${ }^{d}$, Wei Yao ${ }^{b, c, * *}$, Jian Wang ${ }^{a, *}$ \\ a State Key Laboratory of Fire Science, University of Science and Technology of China, Hefei, Anhui, 230026, PR China \\ b State Key Laboratory of High Temperature Gas Dynamics, Institute of Mechanics, Chinese Academy of Sciences, \\ Beijing 100190, PR China \\ ' School of Engineering Science, University of Chinese Academy of Science, Beijing, 100049, PR China \\ d Department of Civil and Architectural Engineering, City University of Hong Kong, Kowloon, Hong Kong
}

\section{H I G H L I G H T S}

- Bluff body augmented micro cavity combustors are numerically investigated.

- Combustion efficiencies of original micro-cavity-combustors improve significantly.

- Altering of flow structure and species mixing are the dominating mechanisms.

- The local Damköhler number characterizes the variation of combustion efficiency.

\section{A R T I C L E I N F O}

Article history:

Received 24 May 2019

Received in revised form

24 November 2019

Accepted 2 December 2019

Available online $\mathrm{xxx}$

Keywords:

Micro combustor

Cavity

Bluff body

Combustion efficiency

Local Damköhler number

\begin{abstract}
A B S T R A C T
Bluff body augmented micro-cavity combustors are proposed in this study to enhance the combustion efficiency under high inlet velocities. The original and two types of bluff body supplemented micro cavity combustors, namely CAVITY, TRIANGLE, and FIN combustors are numerically investigated. The results show that the combustion efficiency $\left(\eta_{c}\right)$ of bluff body augmented combustors are higher than that of the CAVITY combustor, and the largest increment of $10.8 \%$ is obtained in the FIN combustor. The underlying mechanisms for the improvement in $\eta_{c}$ of the FIN and TRIANGLE combustors have been analyzed. It is demonstrated that the altered flow field structures and transvers reactant transport induced by the bluff body play dominant roles. Moreover, the local Damköhler number $\left(D a_{L}\right)$ is introduced, which is defined as the ratio of the local hydrogen reaction rate and the convective mass transport rate. The variation of $\eta_{c}$ along the streamwise direction in the proposed combustors is determined by the value of $D a_{L}$.
\end{abstract}

(C) 2019 Hydrogen Energy Publications LLC. Published by Elsevier Ltd. All rights reserved.

* Corresponding author.

** Corresponding author. State Key Laboratory of High Temperature Gas Dynamics, Institute of Mechanics, Chinese Academy of Sciences, Beijing, 100190, PR China.

E-mail addresses: weiyao@imech.ac.cn (W. Yao), wangj@ustc.edu.cn (J. Wang). 


\author{
Nomenclature \\ A cross-sectional area of the channel at $\mathrm{x}, \mathrm{m}^{2}$ \\ $\mathrm{C}_{p} \quad$ specific heat, $\mathrm{J} /(\mathrm{kg} \cdot \mathrm{K})$ \\ $C_{w} \quad$ specific heat of the wall, $\mathrm{J} /(\mathrm{kg} \cdot \mathrm{K})$ \\ $\mathrm{C}_{2}, \mathrm{C}_{1 \varepsilon} \mathrm{C}_{3 \varepsilon} \mathrm{C}_{1}$ constants for $\varepsilon$ equation \\ $D a_{\mathrm{L}} \quad$ local Damköhler number \\ $D_{k, m} \quad$ binary mass diffusion coefficient of species $k, \mathrm{~m}^{2} / \mathrm{s}$ \\ $\mathrm{G}_{b} \quad$ generation term of $\mathrm{k}$ inducing by buoyance, $\mathrm{kg} /$ \\ $\left(\mathrm{m} \cdot \mathrm{s}^{3}\right)$ \\ $G_{k} \quad$ generation term of $\mathrm{k}$ inducing by shear of mean \\ velocity, $\mathrm{kg} /\left(\mathrm{m} \cdot \mathrm{s}^{3}\right)$ \\ $\mathrm{h} \quad$ enthalpy of the fluid, $\mathrm{J} / \mathrm{kg}$ \\ $h_{0} \quad$ convective heat transfer coefficient, $\mathrm{W} /\left(\mathrm{m}^{2} \cdot \mathrm{K}\right)$ \\ $\dot{\mathrm{H}}_{\text {c.in }}$ flux of total combustion enthalpy of $\mathrm{H} 2$ at the \\ inlet, $\mathrm{W}$ \\ $h_{c} \quad$ combustion enthalpy per unit mass of $\mathrm{H}_{2}, \mathrm{~J} / \mathrm{kg}$ \\ $h_{\text {in }} \quad$ total enthalpy of mixture at inlet \\ $h_{k} \quad$ enthalpy of species $k, \mathrm{~J} / \mathrm{kg}$ \\ HLR heat loss ratios \\ $\mathrm{k} \quad$ turbulent kinetic energy, $\mathrm{m}^{2} / \mathrm{s}^{2}$ \\ $\mathrm{L}_{1} \quad$ overall length of combustors, $\mathrm{mm}$ \\ $\mathrm{L}_{2}$ distance between inlet and entrance of the cavity \\ of combustors, $\mathrm{mm}$ \\ $\mathrm{L}_{3} \quad$ length of the cavity, $\mathrm{mm}$ \\ $\mathrm{L}_{4} \quad$ distance between the bottom of bluff bodies and \\ the cavity trailing edge, $\mathrm{mm}$ \\ $m_{c} \quad$ transverse hydrogen mass flux, $\mathrm{kg} /(\mathrm{m} 2 \cdot \mathrm{s})$ \\ $\dot{m}_{\mathrm{H}_{2}, \text { in }} \dot{m}_{\mathrm{H}_{2}, \mathrm{x}}$ mass flow rate of hydrogen at the inlet and $\mathrm{x}$ \\ location, $\mathrm{kg} / \mathrm{s}$ \\ $p \quad$ pressure, $\mathrm{Pa}$ \\ $q$ heat loss rate, $\mathrm{W}$ \\ Re Reynolds number \\ $\mathrm{R}_{\mathrm{H} 2} \quad$ consumption rate of $\mathrm{H}_{2}, \mathrm{~kg} /\left(\mathrm{m}^{3} \cdot \mathrm{s}\right)$ \\ $R_{k} \quad$ production rate of species $k, \mathrm{~kg} /\left(\mathrm{m}^{3} \cdot \mathrm{s}\right)$ \\ $s \quad$ unit surface, $\mathrm{m} 2$ \\ $\mathrm{Sc}_{\mathrm{t}} \quad$ turbulent Schmidt number \\ $\mathrm{T}_{\infty} \quad$ ambient temperature, $\mathrm{K}$ \\ $\mathrm{t} \quad$ time, $\mathrm{s}$ \\ $\mathrm{T}$ flame temperature, $\mathrm{K}$ \\ $\mathrm{T}_{\max } \quad$ maximum flame temperature, $\mathrm{K}$ \\ $\mathrm{T}_{u} \quad$ unburned gas temperature, $\mathrm{K}$
}

$\mathrm{T}_{\mathrm{w}}$

$T_{0}$

u

$u_{i} u_{j}$

$u_{i}^{\prime} u_{j}^{\prime}$

$v$

$v_{\text {in }}$

$\mathrm{W}_{0}$

$\mathrm{W}_{1}$

$\mathrm{W}_{2}$

$\mathrm{W}_{3}$

$\mathrm{W}_{4}$

$\mathrm{W}_{5}$

$\mathrm{x}$

$x_{i} x_{j}$

$\mathrm{y}$

$\mathrm{Y}_{\mathrm{H}_{2}}$

$Y_{k}$

$Y_{M}$

Greek symbols

$\Delta \dot{H} \quad$ flux of total enthalpy change, W

$\Delta H_{n o r} \quad$ normalized total enthalpy change

$\varepsilon_{r}$

$\eta_{c}$

$\theta_{0}$

$\theta_{1}$

$\lambda_{\text {eff }}$

$\lambda_{w}$

$\mu$

$\mu$

$\mu_{\mathrm{t}}$

$\rho$

$\rho_{w}$

$\sigma$

$\sigma_{k}, \sigma_{\varepsilon}$

$\tau$

$\phi$

$\chi$ velocity component, $\mathrm{m} / \mathrm{s}$ inlet velocity, $\mathrm{m} / \mathrm{s}$

overall width of combustors, $\mathrm{mm}$

depth of the cavity, $\mathrm{mm}$

gap distance between fines, $\mathrm{mm}$

streamwise coordinate

transverse coordinate

mass fraction of the species $\mathrm{H}_{2}$

mass fraction of species $k$

surface radiative emissivity

combustion efficiency

aft angle of the cavity, $45^{\circ}$

angle of the fin, $60^{\circ}$

flow, $\mathrm{W} /(\mathrm{m} \cdot \mathrm{K})$

dynamic viscosity, $\mathrm{kg} /(\mathrm{m} \cdot \mathrm{s})$

turbulent viscosity, $\mathrm{kg} /(\mathrm{m} \cdot \mathrm{s})$

density, $\mathrm{kg} / \mathrm{m}^{3}$

density of the wall, $\mathrm{kg} / \mathrm{m} 3$

Prandtl number for $\mathrm{k}$ and $\varepsilon$

unit volume, $\mathrm{m} 3$

equivalence ratio

reaction progress variable temperature of the wall, $\mathrm{K}$

outer surface temperature of the wall, $\mathrm{K}$ streamwise component of velocity, $\mathrm{m} / \mathrm{s}$

fluctuating components of the velocity, $\mathrm{m} / \mathrm{s}$ transverse component velocity, $\mathrm{m} / \mathrm{s}$

channel height of combustors, $\mathrm{mm}$

wall thickness of combustors, $\mathrm{mm}$

edge length of the regular triangle, $\mathrm{mm}$

coordinates in rectangular coordinate system

dissipation rate of $\mathrm{k}$ contributed by fluctuating

dilatation in compressible turbulence, $\mathrm{kg} /\left(\mathrm{m} \cdot \mathrm{s}^{3}\right)$

dissipation rate of turbulent energy, $\mathrm{m}^{2} / \mathrm{s}^{3}$

effective thermal conductivity of the turbulent

thermal conductivity of the wall, $\mathrm{W} /(\mathrm{m} \cdot \mathrm{K})$

Stephan-Boltzmann constant, $\mathrm{W} /\left(\mathrm{m}^{2} \cdot \mathrm{K}^{4}\right)$

\section{Introduction}

In recent years, with the rapid development of microelectromechanical systems (MEMS), the demand for miniaturizing its power supply system becomes urgent. Compared with traditional chemical batteries, combustion-based micropower generation devices offer the advantage of significantly higher specific energy density [1]. Therefore, microscale combustion has received considerable research interests, and numerous micropower generation devices fueled with hydrogen/hydrocarbon have been designed as one of the promising power sources for MEMS [2-4]. However, compared with the normal-sized combustors, downscaling tends to exacerbate the technical challenges in sustainably

stable yet high-efficiency combustion in the micro combustors. The heat loss to the walls [5-7] and radical quenching $[8,9]$ can be pronounced due to the linearly increased area-tovolume ratio with the decreasing of combustor size, which could lead to combustion instability and even flame extinction [10-12]. In addition, the residence time for the reactant mixture reduces significantly in micro scale combustors, which decreases the combustion efficiency as the fuel flow rate increases $[13,14]$.

To achieve a wide flame stability scope and high combustion efficiency in micro combustors, different strategies have been proposed. The "Swiss-roll" structure [15], porous media $[16,17]$ and multichannel $[18,19]$ are applied in micro combustors to achieve heat recirculation between the reaction zone and solid structures, where the negative effects of heat 
loss on flame stability and combustion efficiency are compensated by the "excess enthalpy" combustion [20]. Catalytic combustion [21-23] is also proven to be promising in micro combustors with the advantages of the large surfacearea-to-volume ratio and the suppression of radical depletion [24]. However, the catalytic combustors have the evident weakness of high costs and limited service life.

Besides heat recirculation and catalytic combustion, flow modulation has been proven to be an effective approach to anchor the flame and thus improve flame stability. The flame holders frequently adopted in normal-scale combustors, such as backward-facing step, bluff body, and cavity have also been widely investigated for the micro-combustors. The backwardfacing step configuration was adopted in a micro-combustor by Yang et al. [25]. According to their experiments in cylindrical micro-combustor with a backward-facing step, high yet uniform wall temperature was observed for a wide operating range of flow rates and equivalence ratios. Given the excellent performance in wall temperature distribution, the backward facing step has been widely employed in microthermophotovoltaic (MPTV) systems [26-29]. Besides, Wan et al. $[30,31]$ developed a micro-combustor aided by a bluff body, with significantly extends the blow-off limits of premixed hydrogen/air and methane/air flames through the coupled effects of recirculation zone, preheating, and preferential transport. The effects of blockage ratio [32] and shape of bluff-body $[33,34]$ on the flame stability have been studied as well to guide the optimization of the bluff-body aided microcombustors. Besides, $\mathrm{O}_{2}$ enhancement [35] and $\mathrm{H}_{2}$ assistance [36] combustion were adopted in bluff-body combustors to improve the thermal performance attributed to the enhanced combustion kinetics. Recently, Yan et al. [37] proposed a bluffbody with slits on both sides in micro-combustor, which improves the combustion efficiency and velocity extinction limit compared with the traditional bluff-body due to the enlarged recirculation zone induced by the bluff-body. The effects of structure parameters, the slit width and the angle of controllable flow on combustion characteristics were analyzed as well [38]. Nevertheless, it should be noted that high wall temperature regions will shrink and move downstream apparently as the inlet velocity increases in those bluff-body type combustors, as reported in the studies. The nonuniformity of wall temperature can be detrimental to the combustor structure due to the induced thermal stress.

The micro cavity-combustors were observed to have better flame stability along with uniform temperature distribution [39-41], indicating its potential in micro propulsion and MTPV systems. Li et al. [42] studied the synergistic effects of catalyst segmentation and cavities in premixed methane/air micro combustor, where the flame stability and combustion efficiency have improved significantly with the aid of the etching cavities. Moreover, the non-catalytic meso/micro combustor with cavities were investigated extensively. The studies on the combustion characteristics of $\mathrm{H}_{2} /$ air and $\mathrm{CH}_{4} /$ air mixture in microchannels with cavities [43-52] pointed out that the flame blow-off limit was extended over several times compared with traditional straight micro-channel combustors. While the flame stabilities of both $\mathrm{CH}_{4} /$ air and $\mathrm{H}_{2}$ /air fueled combustors were extended evidently, though their flame behaviors were quite different. The $\mathrm{CH}_{4} /$ air premixed flame $[44,45]$ splits at the end of the ramped cavity and blows off subsequently with the increase of inlet velocity. Concerning the lean $\mathrm{H}_{2}$ /air microcavity combustor [47-49], the flame was split in the tip before the flame blow-off occurred with the increasing of inlet velocity. As a result, the combustion efficiency reduces significantly as fuel leaks from the opened tip without combustion. Therefore, alleviating the "flame tip split" phenomenon is crucial for the lean $\mathrm{H}_{2}$ /air fueled micro-cavity combustor to improve its combustion efficiency. The investigation on the effects of initial conditions of inlet flow, such as temperature [47], pressure [48] and oxygen proportion [50] indicated that a higher inlet temperature and oxygen proportion and an appropriate pressure condition are beneficial for improving the combustion efficiency. In addition, effects of wall materials were also considered. A non-monotonic effect of thermal conductivity on combustion efficiency was concluded [46], and a double layer wall assembled with different materials was proposed to improve the performance of single layer combustors [51]. Moreover, structure optimizing is worthy of further investigation, which is more feasible in practical application. The lean hydrogen/air fueled micro-cavity combustors with various cavity depth were investigated [49], inverse dependence was observed for the combustion efficiency and the cavity depth at relatively low and high inlet velocities, respectively. The study on the effects of cavity aft ramp angle, $\theta$ [52], found that the $\theta=90^{\circ}$ cavity possesses a higher reaction rate, however, the flame is prone to be interrupted at the end of the cavity with high strain rate and may lead to a dramatical decline in combustion efficiency if the inlet velocity is high.

The abovementioned structure optimizing efforts on the micro-cavity combustor mainly focuses on the cavity. As the "flame tip splitting" phenomenon appears in the downstream of the cavity, the structure optimizing in this part is a natural choice. Therefore, in this study, a new type of micro channel combustor that combines the bluff-body and cavity has been proposed to improve the performance, especially the combustion efficiency of the original micro cavity-combustors. Considering the excellent capability in flame anchoring proven by the previous studies, a bluff body is placed behind the cavity to suppress the flame split and increase the combustion efficiency. The combustion efficiency and flame structures of hydrogen/air premixed micro cavity-combustors with and without bluff bodies are investigated numerically with various inlet velocities. The characteristics of thermal coupling, species transport and chemical reactions in the proposed combustors with different types of auxiliary bluff bodies are analyzed to further provide guidelines for the optimization of micro-combustors.

\section{Numerical methodology}

\section{Geometric model}

The micro combustors to be studied are schematically shown in Fig. 1. The geometry of oppositely located dual-cavity micro combustor is designed following the experimental work of Fan et al. [41]. The overall length $\left(L_{1}\right)$, width $\left(W_{0}\right)$, and channel height $\left(W_{1}\right)$ of the combustors are $18 \mathrm{~mm}, 20 \mathrm{~mm}$, and $1 \mathrm{~mm}$, respectively. The cavity locates at $3 \mathrm{~mm}\left(\mathrm{~L}_{2}\right)$ away from the 


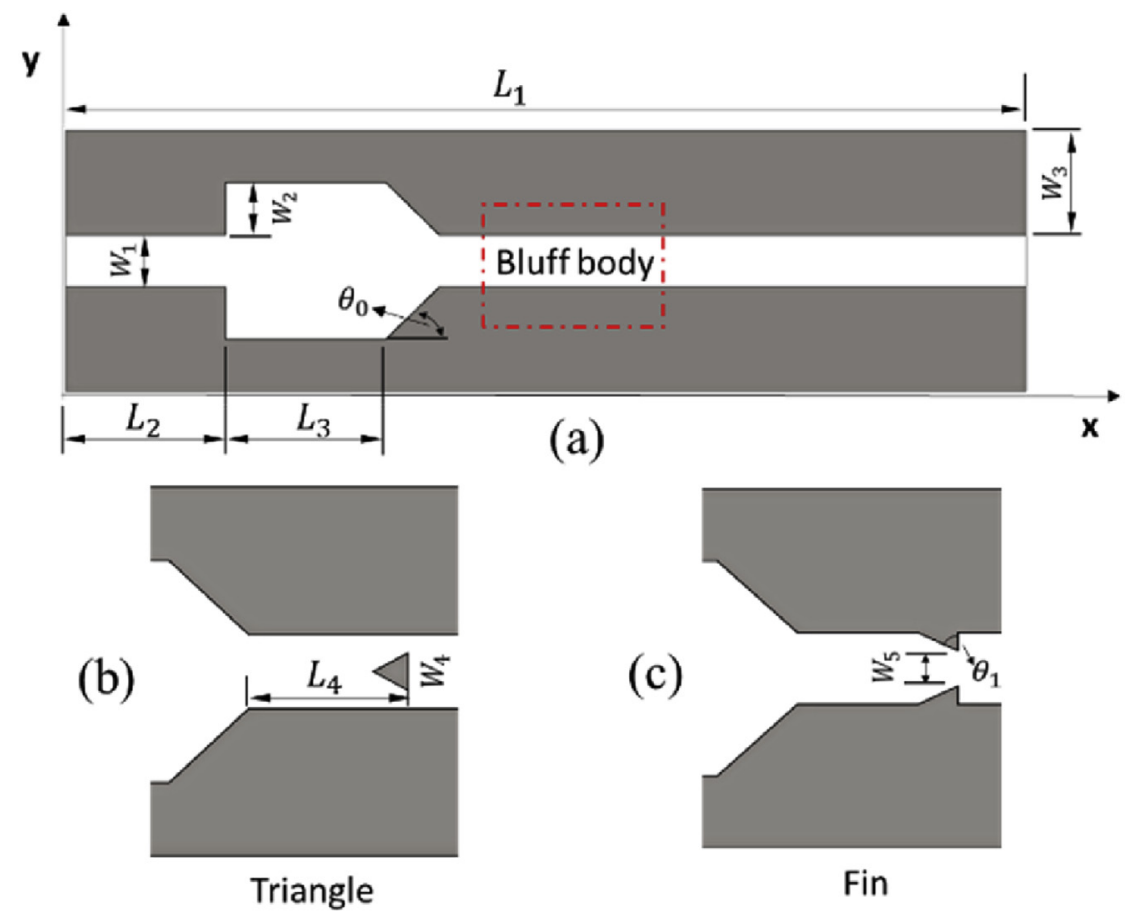

Fig. 1 - Schematic diagrams of the (a) CAVITY, (b) TRIANGLE, and (c) FIN combustors.

combustor inlet. The length $\left(L_{3}\right)$ and depth $\left(\mathrm{W}_{2}\right)$ of the cavity are $3 \mathrm{~mm}$ and $1 \mathrm{~mm}$ with an aft angle $\left(\theta_{0}\right)$ of $45^{\circ}$. The wall thickness $\left(\mathrm{W}_{3}\right)$ is $2 \mathrm{~mm}$. Two different types of bluff bodies were employed in the present study, i.e., the regular triangle mounted on the center and the fin mounted on the inner surface of the micro-channel. The blockage ratio of the bluff body installed behind the cavity is maintained 0.5 in all the cases. Therefore, the edge length $\left(\mathrm{W}_{4}\right)$ of the regular triangle and the gap distance $\left(\mathrm{W}_{5}\right)$ between the fins are equally $0.5 \mathrm{~mm}$. The angle of the fin $\left(\theta_{1}\right)$ is $60^{\circ}$, i.e., the fin is half of the regular triangle. The distance $\left(L_{4}\right)$ between the bottom of different bluff bodies and the cavity trailing edge is $2 \mathrm{~mm}$. For convenience, the combustors with pure dual cavities, combined with regular triangle and fin are termed as CAVITY, TRIANGLE, and FIN, respectively hereinafter.

\section{Computational model}

Considering the large width to height ratio $\left(\frac{W_{1}}{W_{0}}=20\right)$, a twodimensional numerical model is used to simulate the combustion of premixed hydrogen/air mixture in the micro combustors, as shown in Fig. 1. The continuum assumption of fluid is applicable as the characteristic length scale of the combustors in this study is sufficiently larger than the molecular mean free path of the gas flowing through the combustor. Thus, Navier-Stokes equations are valid for the current simulations. For the combustors scale down to micro scales, the flame is prone to embody unstable and turbulent behaviors even under a laminar inflow condition due to the strong interactions between heat, flow and chemical reactions, which has been observed in many numerical $[53,54]$ and experimental $[10,55]$ studies. Besides, according to the study of Kuo and Ronney [56] on "Swiss-roll" heat recirculating micro combustor, the modeling of turbulent effect is required for Reynolds number (Re) larger than 500. For the examined combustors in this study, Re is larger than 500 at inlet velocity above $8 \mathrm{~m} / \mathrm{s}$. To account for the turbulence effect, realizable $\mathrm{k}-\varepsilon$ turbulent model is adopted in the present study. The capability of this two equation turbulence model has been confirmed in previous study of micro-combustors with cavity $[39,57]$ and bluff-body $[37,58]$ structures. The computational domain is comprised of the fluid region and solid structures, heat conduction in the solid walls solved to account for the strong thermal coupling between the wall and the fluid flow in the micro combustors [59]. The Reynolds-averaged governing equations for gas phase and wall are shown below.

Continuity equation:

$\frac{\partial \bar{\rho}}{\partial \mathrm{t}}+\frac{\partial \overline{\rho u_{i}}}{\partial x_{i}}=0$

Momentum equation:

$\frac{\partial \overline{\rho u_{j}}}{\partial t}+\frac{\partial}{\partial x_{i}}\left(\overline{\rho u_{i} u_{j}}\right)+\frac{\partial \overline{\rho u_{i}^{\prime} u_{j}^{\prime}}}{\partial x}=\frac{\partial}{\partial x_{i}}\left(\mu \frac{\partial \overline{u_{i}}}{\partial x_{j}}\right)-\frac{\partial \bar{p}}{\partial x_{j}}$

Energy equation:

$$
\begin{aligned}
& \frac{\partial \overline{\rho h}}{\partial \mathrm{t}}+\frac{\partial}{\partial x_{i}}\left(\overline{\rho u_{i} h}\right)=\frac{\partial}{\partial x_{i}}\left(\frac{\lambda_{\text {eff }}}{C_{p}} \frac{\partial \bar{h}}{\partial x_{i}}\right)+\frac{\partial}{\partial x_{i}} \sum_{k} h_{k} \overline{J_{k}}+\sum_{k} h_{k} R_{k} \\
& \frac{\partial}{\partial x_{i}}\left(\lambda_{w} \frac{\partial T_{w}}{\partial x_{i}}\right)=\frac{\partial\left(\rho_{w} C_{w} T_{w}\right)}{\partial t}
\end{aligned}
$$




\section{Species equation:}

$\frac{\partial \bar{\rho} Y_{k}}{\partial t}+\frac{\partial}{\partial x_{i}}\left(\overline{\rho u_{i}} Y_{k}\right)=\frac{\partial}{\partial x_{i}}\left[\left(\bar{\rho} D_{k, m}+\frac{\mu_{t}}{S c_{t}}\right) \frac{\partial Y_{k}}{\partial x_{i}}\right]+R_{k}$

where $\rho, \mathrm{t}$ and $p$ denote the density, time and pressure, respectively; $u_{i}$ is the velocity component in $i$ direction; $x_{i}$ and $u_{i}^{\prime}$ denote the coordinate in rectangular coordinate and fluctuating component of velocity, respectively; $\mu, C_{p}, h$ are the dynamic viscosity, specific heat, and enthalpy of the fluid; $\lambda_{\text {eff }}$, $\mu_{\mathrm{t}}$ and $\mathrm{Sc}_{\mathrm{t}}$ represent the effective thermal conductivity, turbulent viscosity and Schmidt number, respectively. $J_{k}$ is the diffusive flux of species $k$, as presented in the first term of the right-hand side of Eq. (5). $Y_{k}, D_{k, m}, h_{k}$ and $R_{k}$ are the mass fraction, binary mass diffusion coefficient, sensible enthalpy and reaction rate of species $k$, respectively; Besides, the density, specific heat, temperature and thermal conductivity of the wall are termed as $\rho_{w}, C_{w}, T_{w}$ and $\lambda_{w}$, respectively.

For the realizable $\mathrm{k}-\varepsilon$ turbulence model, two additional transport equations of turbulent kinetic energy $(\mathrm{k})$ and its dissipation rate $(\varepsilon)$ are solved to close the Reynolds-averaged Navier-Stokes equations.

$$
\begin{aligned}
& \frac{\partial}{\partial \mathrm{t}}(\rho \mathrm{k})+\frac{\partial}{\partial x_{j}}\left(\rho \mathrm{k} u_{\mathrm{j}}\right)=\frac{\partial}{\partial x_{j}}\left[\left(\mu+\frac{\mu_{\mathrm{t}}}{\sigma_{\mathrm{k}}}\right) \frac{\partial \mathrm{k}}{\partial x_{j}}\right]+G_{k}+G_{b}-\rho \varepsilon-\mathrm{Y}_{\mathrm{M}} \\
& \frac{\partial}{\partial \mathrm{t}}(\rho \varepsilon)+\frac{\partial}{\partial x_{\mathrm{j}}}\left(\rho \varepsilon u_{\mathrm{j}}\right)=\frac{\partial}{\partial x_{j}}\left[\left(\mu+\frac{\mu_{\mathrm{t}}}{\sigma_{\varepsilon}}\right) \frac{\partial \varepsilon}{\partial x_{j}}\right]+\rho C_{1} S \varepsilon-\rho C_{2} \frac{\varepsilon^{2}}{\mathrm{k}+\sqrt{v \varepsilon}} \\
& \quad+C^{1 \varepsilon} \frac{\varepsilon}{\mathrm{k}} C_{3 \varepsilon} G_{b}
\end{aligned}
$$

where $\sigma_{k}$ and $\sigma_{\varepsilon}$ are Prandtl numbers for $\mathrm{k}$ and $\varepsilon$ respectively; $G_{k}$ and $G_{b}$ denote the generation terms of $\mathrm{k}$ inducing by shear of mean velocity and buoyance respectively; $Y_{M}$ represents the dissipation rate of $\mathrm{k}$ attributed to fluctuating dilatation in compressible turbulence.; $C_{1}, C_{2}, C_{1 \varepsilon}$ and $C_{3 \varepsilon}$ are constants.

The ideal gas law and mixing law are employed to calculate the density and specific heat of the gaseous mixture. The thermal conductivity and viscosity of the fluid are determined as mass fraction-weighted averages of the individual properties of all species. For each species, the specific heat is calculated using a piecewise polynomial fit of temperature. Besides, the kinetic theory is used to calculate the thermal conductivity, viscosity, and diffusivity of pure species.

For boundary conditions, the premixed $\mathrm{H}_{2}$ /air with uniform velocity distribution and initial temperature of $300 \mathrm{~K}$ is specified at the inlet of the combustor, and the equivalence ratio $(\varphi)$ of the mixture is set to 0.5 unless specifically stated. The pressure outlet boundary with ambient pressure is imposed at the outlet. The thermal conditions of inner walls are coupled with the outer surface of the fluid zone, and non-slip and zero species flux boundary conditions are specified. The discrete ordinates (DO) radiation model is applied to conclude the radiation between the inner surfaces [44]. For the outer combustor surfaces with temperature of $\mathrm{T}_{\mathrm{O}}$, the heat loss from outer wall to the ambient consists of both convective and radiative parts is calculated by

$q=h_{o}\left(\mathrm{~T}_{\mathrm{O}}-\mathrm{T}_{\infty}\right)+\varepsilon_{r} \sigma\left(\mathrm{T}_{\mathrm{O}}^{4}-\mathrm{T}_{\infty}^{4}\right)$

where the convective heat transfer coefficient, $h_{0}$, surface emissivity, $\varepsilon_{r}$, and ambient temperature, $\mathrm{T}_{\infty}$, are set to $20 \mathrm{~W} /$ $\left(\mathrm{m}^{2} \cdot \mathrm{K}\right), 0.92$ and $300 \mathrm{~K}$, respectively [30]. The value of StephanBoltzmann constant, $\sigma$, is $5.67 \times 10^{-8} \mathrm{~W} /\left(\mathrm{m}^{2} \mathrm{~K}^{4}\right)$.

A detailed mechanism [60] consisting of 13 species and 19 reversible elementary reactions is adopted for homogenous combustion of $\mathrm{H}_{2}$ /air mixture, whereas the heterogeneous reactions on combustor wall are neglected. Thermodynamic and transport properties of the pure species are acquired from the database of Sandia National Laboratories [61,62]. Fluent 6.3 is used to solve the conservation equations of mass, momentum and energy, along with the species transport equations. The second-order upwind scheme is applied for the discretization of the convection terms. The coupled pressure and velocity is solved by the SIMPLE algorithm. The convergence criteria based on absolute residuals is $1 \times 10^{-6}$ for all equations.

\section{Grid independence and model validation study}

The multi-block structured quadrilateral mesh was applied with further refinement in regions near shear layers for three types of micro-combustors. Three mesh sets were generated for the CAVITY combustor to ensure the grid convergence, where the cell numbers of the coarse, medium and fine meshes are 23,086, 38,500 and 73,343, respectively. The hydrogen mass fraction along the centerline and the temperature of the external wall of the CAVITY combustor are compared for the three mesh sets at the inlet velocity of $10 \mathrm{~m} /$ s. As shown in Fig. 3a, inconspicuous difference for the profiles of $\mathrm{H}_{2}$ mass fraction along the centerline and the external wall temperature can be observed, indicating the convergence of the computational grid. Consequently, the medium level mesh of 38,500 cells, as a balance of computational cost and accuracy, is used in the subsequent modeling. The mediumlevel mesh has a minimum size of $20 \mu \mathrm{m}$ and an average mesh size of $50 \mu \mathrm{m}$, as illustrated in Fig. 2.

To validate the numerical model used in this study, the exhaust gas temperatures of the CAVITY combustor are validated against the experimental data and the numerical results by Wan et al. [41] and Su et al. [39] at $\varphi=0.3$ under various inlet velocities. As depicted in Fig. $3 b$, though the present simulation shows relatively larger discrepancies compared with the experimental data at low inlet velocities, agreements between the present results with experimental measurements are remarkably improved at higher inlet velocities. A possible explanation for this discrepancy may lie in the systemic error in the temperature measurement. The reading of the thermal couple is always lower than the exact value of the flame temperature due to the radiative heat loss according to previous study [63]. An underestimate of the ratio of the surface emissivity to convective heat transfer coefficient in the temperature correction can result a lower exhaust gas temperature, especially in high-temperature situations, as is the case in the differences between the numerical and experimental results. Moreover, the numerical results show good agreements both qualitatively and quantitatively with the numerical results obtained in the same micro cavitycombustor in Refs. [39,41]. Therefore, the present computational methodology is applicable, especially at high inflow velocity region, which will be the main concern for the present study. 

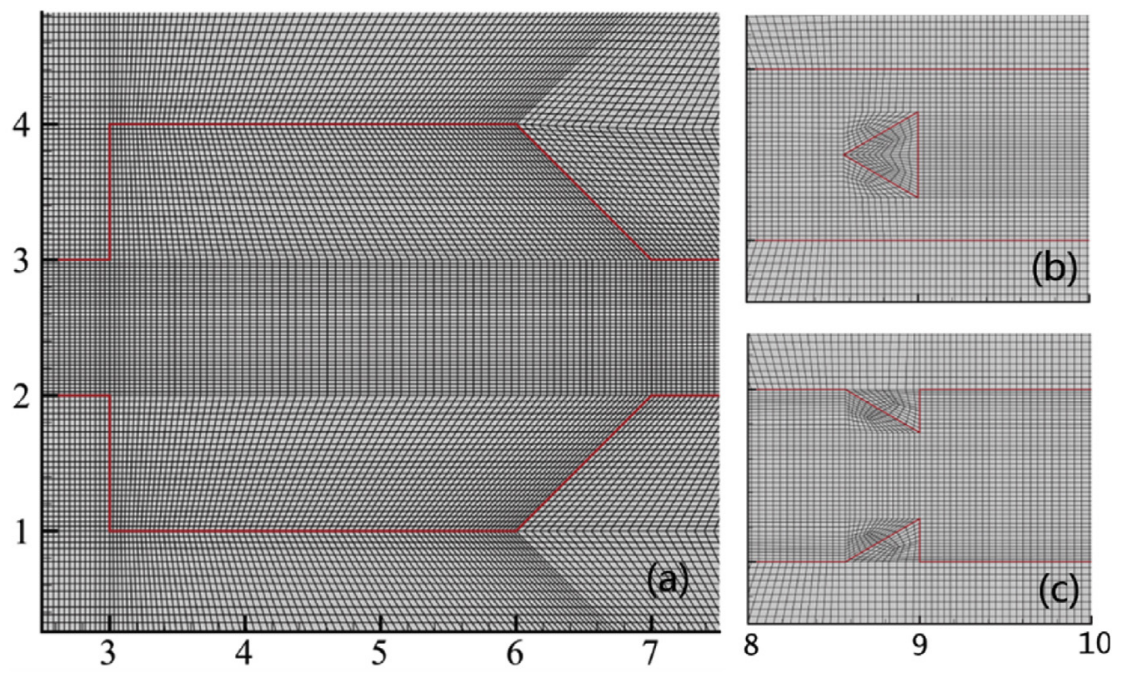

Fig. 2 - The mesh for the two-dimensional (2-D) micro-combustors near (a) the cavity zone, (b) the bluffbody zone, and (c)the hin zone.
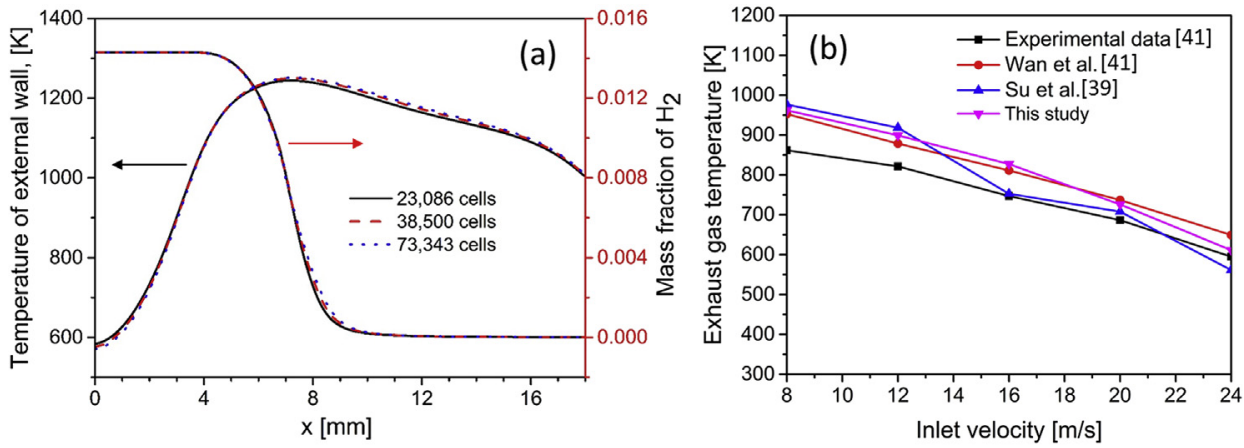

Fig. 3 - (a) Grid independence study and (b) comparison of exhaust gas temperature between numerical and experimental results.

\section{Results and discussion}

\section{Performances of different combustor layouts}

The overall combustion efficiencies at the outlet of the combustors with different layout are shown in Fig. 4. The combustion efficiency $\left(\eta_{c}\right)$ of the combustor at streamwise location $x$ is defined based on the conversion rate of $\mathrm{H}_{2}$ :

$\eta_{\mathrm{c}}=\frac{\dot{m}_{\mathrm{H}_{2}, \mathrm{in}}-\dot{\mathrm{m}}_{\mathrm{H}_{2}, \mathrm{x}}}{\dot{m}_{\mathrm{H}_{2}, \mathrm{in}}} \times 100 \%=\frac{\left[\int \mathrm{Y}_{\mathrm{H}_{2}} \rho \mathrm{udA}\right]_{\mathrm{x}}^{0}}{\left[\int \mathrm{Y}_{\mathrm{H}_{2}} \rho \mathrm{udA}\right]_{(\mathrm{x}=0)}} \times 100 \%$

where $\rho$ is the density of the mixture, $u$ is the $x$ component of velocity, $\dot{m}_{\mathrm{H}_{2} \text {,in }}$ and $\dot{m}_{\mathrm{H}_{2}, \mathrm{x}}$ are the mass flow rate of hydrogen through the channel at inlet and $x$ location, $\mathrm{Y}_{\mathrm{H}_{2}}$ is the mass fraction of the species $\mathrm{H}_{2}$, A is the cross-sectional area of the channel at $x$ location. It can be seen that under relatively low inlet velocities $\left(v_{\text {in }}=12-20 \mathrm{~m} / \mathrm{s}\right)$, the combustion efficiencies are close to $100 \%$ and decrease slightly with further increase in inlet velocity. The combustion efficiencies decrease with almost the same rate regardless of the combustor layout for

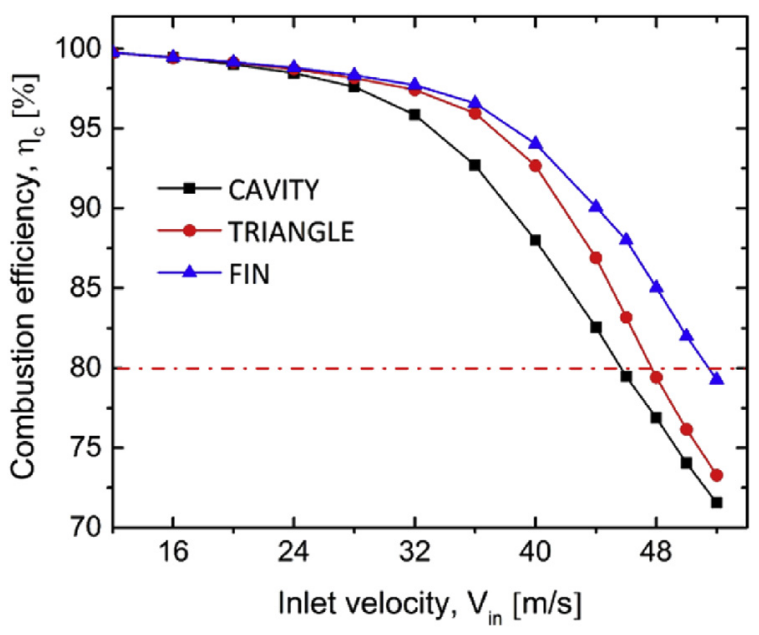

Fig. 4 - Variations of combustion efficiency at different inlet velocities for different combustor layouts. 
inlet velocities less than $20 \mathrm{~m} / \mathrm{s}$. As the inlet velocity further increases, the combustion efficiency decreases rapidly. It can be clearly observed that the decreasing rate is affected by the combustor configurations. With bluff body inserted behind the cavity, the combustion efficiencies have improved compared to the traditional cavity combustor with pure dual cavities. The improvement in combustion efficiency of bluff body augmented combustors becomes prominent as the inlet velocity further increases. The FIN combustor exhibits a continuous increase on the increment of combustion efficiency as velocity increases and gains the largest increment of $10.8 \%$ compared with the CAVITY combustor at $v_{\text {in }}=52 \mathrm{~m} / \mathrm{s}$. Whereas, a non-monotonous variation of the increment of $\eta_{c}$ is observed for TRIANGLE combustor, which achieved the largest increment of $5.4 \%$ at $v_{\text {in }}=40 \mathrm{~m} / \mathrm{s}$. Moreover, according to the definition from Wan et al. [41], the "flame splitting limit" of inlet velocity is at $\eta_{c}=0.8$. Accordingly, the flame splitting limit of CAVITY, TRIANGLE, and FIN combustors are around $46 \mathrm{~m} / \mathrm{s}$ (45 m/s in Ref. [41]), $48 \mathrm{~m} / \mathrm{s}$ and $52 \mathrm{~m} / \mathrm{s}$, respectively.

Variations of combustion efficiencies along the streamwise direction for different combustors with inlet velocity ranging from 16 to $40 \mathrm{~m} / \mathrm{s}$ are shown in Fig. 5, where the region between the blue dash lines indicates the cavity zone ( $x=3 \sim 7 \mathrm{~mm}$ ) and the red dash line denotes the end position of the bluff body ( $x=9 \mathrm{~mm}$ ). The combustion efficiency profiles have three distinguishable regions, i.e., the preheat region, the quick increasing region, and the plateau region. The preheat region represents the preheat zone in which the reactants are heated up, whereas almost no $\mathrm{H}_{2}$ consumed. By comparing Fig. $5 \mathrm{a}-\mathrm{d}$, it can be found that with the increase of inlet velocity, the growth rate of combustion efficiency along the flow direction slows down. Besides, the length of plateau region shortens and even vanished at $v_{\text {in }}=40 \mathrm{~m} / \mathrm{s}$, resulting in the declines of combustion efficiency at the combustor outlet. As shown in Fig. 5a, the combustion efficiencies of different micro-combustors at relatively low velocity are less influenced by the bluff body, and the final combustion efficiencies at the combustor outlet are almost identical. With further increase of the inlet velocity, the profiles of combustion efficiencies along the streamwise direction of different combustors become significantly different in the region behind the bluff body as shown in Fig. $5 c$ and d. Among them, the FIN combustor exhibits the highest combustion efficiency till the combustor outlet, while the $\eta_{c}$ profile of TRIANGLE combustor undergoes a relative decreasing before exceeding that of the CAVITY combustor. In addition, it is noted that the combustion efficiencies profiles of different combustors are almost overlapped ahead of the bluff body, implying that the effects of the bluff body in enhancing combustion efficiency are limited in the downstream region of the bluff bodies. Consequently, the effects of the bluff body on combustion efficiency become more pronounced as a larger fraction of inlet hydrogen is consumed in regions behind the bluff body with increased inlet velocity.

To gain more insight into the sharply descending in combustion efficiency at relatively high inlet velocities and the effects of the bluff body, the contours of mass fraction of $\mathrm{OH}$ and the flame front structures (white dash line) for different combustors at $v_{\text {in }}=24 \mathrm{~m} / \mathrm{s}$ and $40 \mathrm{~m} / \mathrm{s}$ are shown in Fig. 6 . The flame front is defined by the reaction progress variable, $\chi$, which shows good continuity in illustrating the structures of the flame front in the lean hydrogen/air Bunsen flame [64].
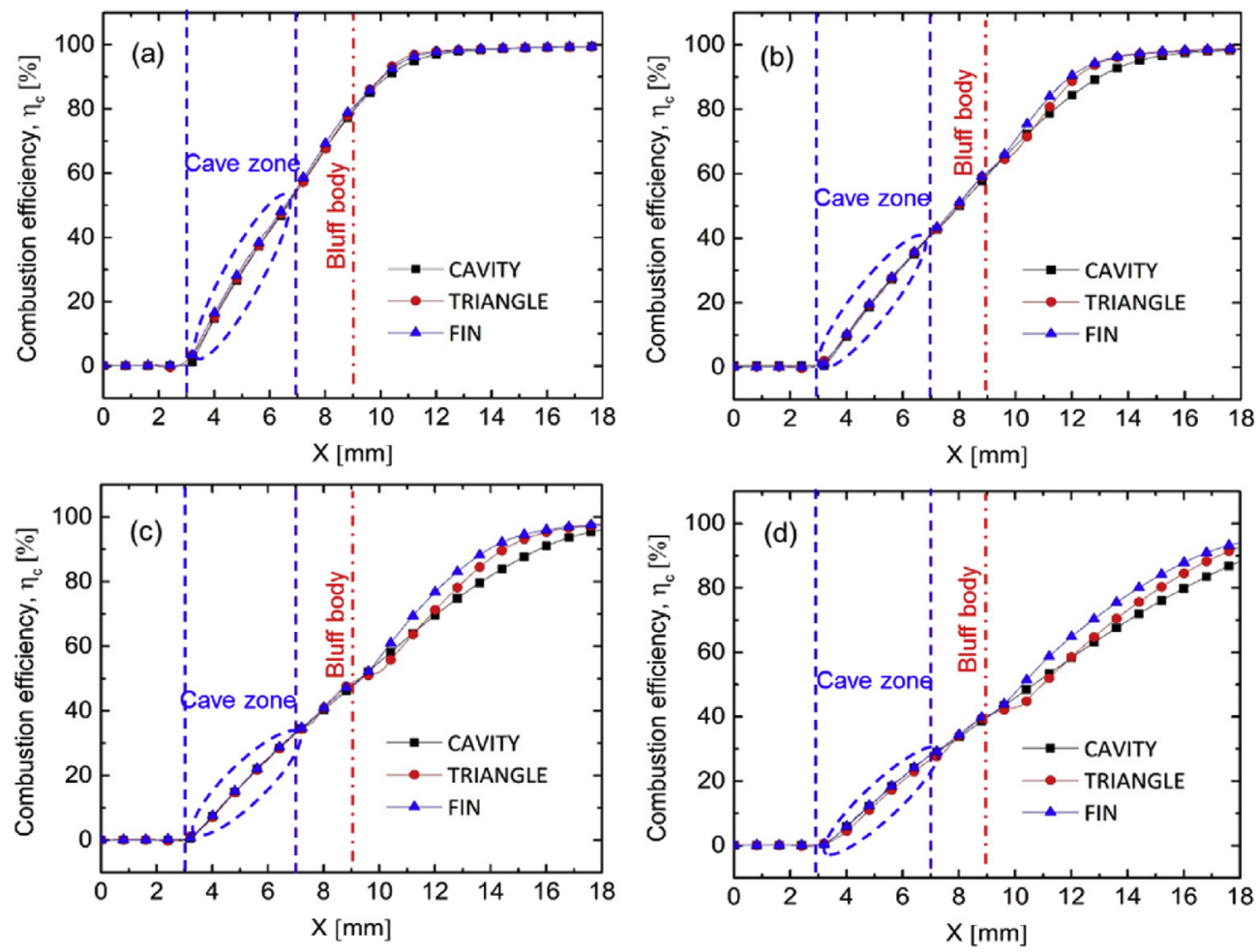

Fig. 5 - Combustion efficiency distribution along the streamwise direction for (a) $v_{\text {in }}=16 \mathrm{~m} / \mathrm{s}$, (b) $v_{\text {in }}=24 \mathrm{~m} / \mathrm{s}$,(c) $v_{\text {in }}=$ $32 \mathrm{~m} / \mathrm{s}$, and $(\mathrm{d}) v_{\text {in }}=40 \mathrm{~m} / \mathrm{s}$. 


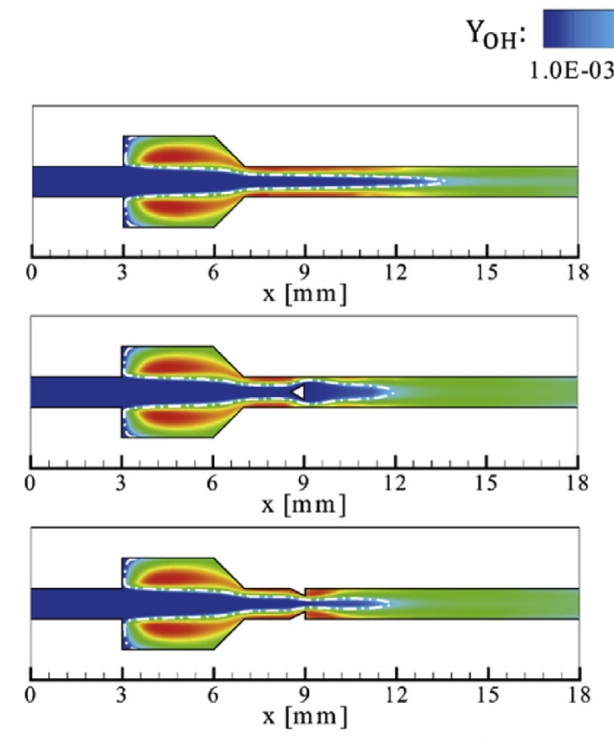

(a) $\mathrm{v}_{\text {in }}=24 \mathrm{~m} / \mathrm{s}$
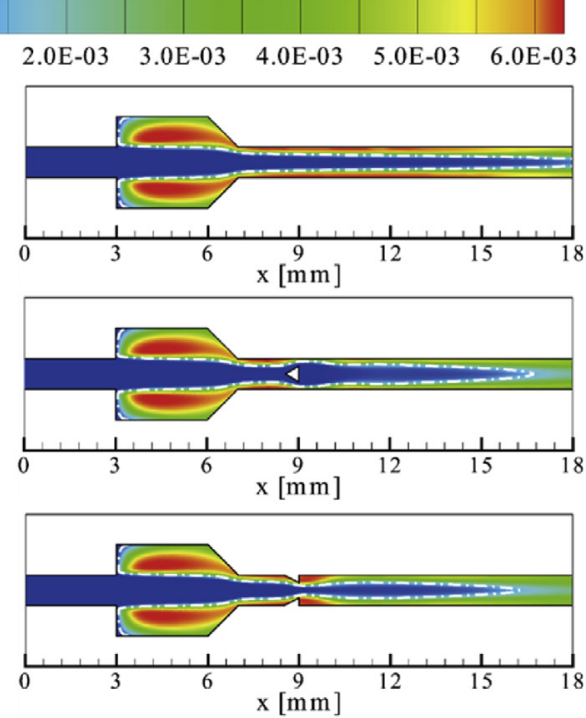

(b) $\mathrm{v}_{\text {in }}=40 \mathrm{~m} / \mathrm{s}$

Fig. 6 - Mass fraction contours of OH with overlaid flame fronts (red dash line) for (a) $v_{\text {in }}=24 \mathrm{~m} / \mathrm{s}$ and (b). (For interpretation of the references to color in this figure legend, the reader is referred to the Web version of this article.) $v_{\text {in }}=40 \mathrm{~m} / \mathrm{s}$

The reaction progress variable is defined as the dimensionless flame temperature, $T$, normalized by the maximum flame temperature $T_{\max }$ and the unburned gas temperature $T_{u}$ :

$\chi=\frac{T-T_{u}}{T_{\max }-T_{u}}$

The white dash contour line at $\chi=0.6$ visualizes the flame front structure, which approximately coincides with the contour of $\mathrm{OH}$ concentration.

As shown in Fig. 6, the reaction zones indicated by $\mathrm{OH}$ distributions are located in the cavity and the downstream boundary layer. In the region before the bluff body, the $\mathrm{OH}$ distribution seems to be independent with the inserted bluff body, which is consistent with the overlapped combustion efficiency profiles before the end of bluff bodies depicted in Fig. 5. For the region behind the bluff body, the $\mathrm{OH}$ mass fraction distribution is obviously altered by the bluff body as also characterized by the variation of the flame front structures. It is noteworthy that contrary to the conventional bluff body stabilized flame mode [30,65], the flame is formed in the side region rather than the wake area for the TRIANGLE combustor. As shown in Fig. 6a, with bluff body mounted, the $\mathrm{OH}$ radicals in the downstream boundary layer is concentrated upwards. Meanwhile, the position of flame tips moves upstream from $x=13.8 \mathrm{~mm}$ to approximately $x=12 \mathrm{~mm}$ and $11.2 \mathrm{~mm}$ for the TRIANGLE and FIN combustors, respectively. In this respect, it can be deduced that the bluff body structure could be beneficial to shorten the traditional micro-cavity combustors. With the velocity increasing from $24 \mathrm{~m} / \mathrm{s}$ to $40 \mathrm{~m} / \mathrm{s}$ shown in Fig. $6 \mathrm{~b}$, the flames are greatly prolonged for the TRIANGLE and FIN combustors and even split at the flame tips for the CAVITY combustor. The prolonged flame and flame-tip opening respectively result in the shrink of effective reaction zone and the leakage of hydrogen, which are responsible for the reduction of combustion efficiency at high inlet velocity. This flame splitting phenomenon has also been observed in previous experimental and numerical studies in micro/meso scale combustion $[66,67]$. Nevertheless, the flame is still anchored in the cavity whereas flame tip split occurred, and no flame blow-off is observed within the simulated conditions. The results manifest the excellent performance of the micro-combustors with cavities in terms of flame stability. Besides, with the aid of a bluff body behind the cavity, the combustor's performance improves significantly. Among the three combustor layouts, the FIN combustor has the highest combustion efficiency and shortest flame length.

\section{Temperature distribution and heat loss analysis}

The thermal coupling between the flame and solid wall is essential for the flame stabilization and in improvement of combustion efficiency in the micro combustor. To investigate the effects of the bluff bodies on thermal coupling, temperature contours for different combustor layouts are shown in Fig. 7, where relatively high inlet velocities of $24 \mathrm{~m} / \mathrm{s}$ and $40 \mathrm{~m} /$ $\mathrm{s}$ are selected to illustrate the differences between various combustors in unsplit and split statuses. High-temperature zones are formed in the cavities and the boundary layers, which are coincided with the $\mathrm{OH}$ distributions shown in Fig. 6. The temperature distributions in the upstream of bluff bodies are almost the same regardless of the combustor configurations, while the gas temperature behind the bluff bodies is notably altered due to the effects of the bluff bodies on flow field structures and reactions modulation. For all combustor layouts, the temperatures in the center regions decline rapidly as the inlet velocity increases from 24 to $40 \mathrm{~m} / \mathrm{s}$, which is caused by the prolonged flame and the reduced combustion efficiency. As for the temperature distributions in solid wall, the discrepancy among the combustors are small and mostly limited to the region behind the bluff body. As shown in Fig. 7 , 


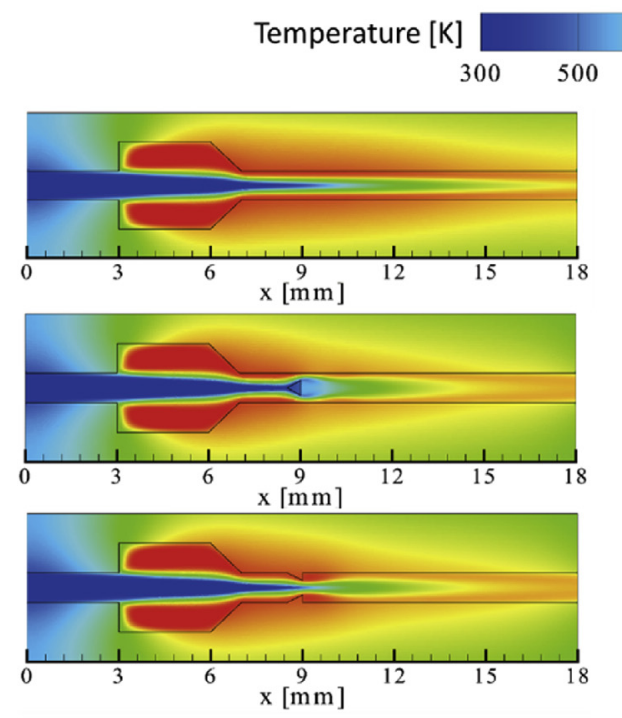

(a) $v_{\text {in }}=24 \mathrm{~m} / \mathrm{s}$
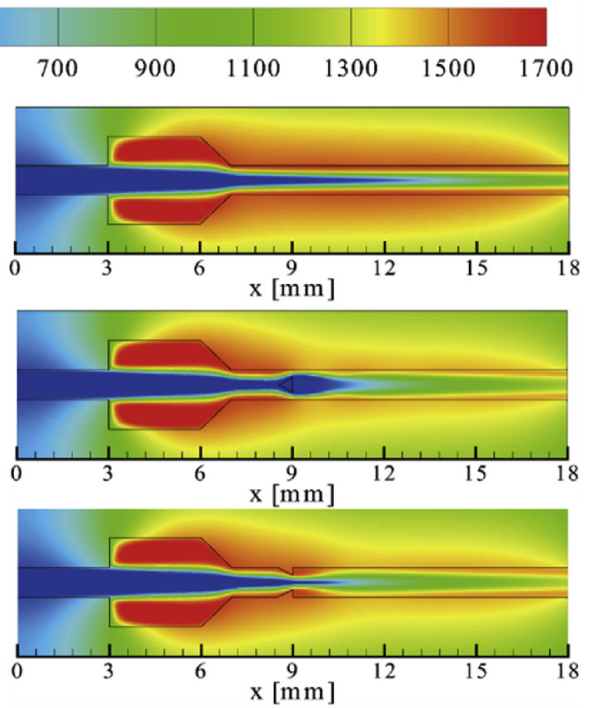

(b) $\mathrm{v}_{\text {in }}=40 \mathrm{~m} / \mathrm{s}$

Fig. $7-$ Temperature contours at $v_{\text {in }}=24 \mathrm{~m} / \mathrm{s}$ and (b) $v_{\text {in }}=40 \mathrm{~m} / \mathrm{s}$

the wall temperature of the combustor with an inserted bluff body is lower than that of the CAVITY combustor. This discrepancy is mainly due to the lower temperature in the boundary regions behind bluff body, which directly alters the heat transfer between the flame and wall.

In order to quantify the thermal coupling in different combustor layouts, the normalized total enthalpy change $\left(\Delta H_{n o r}\right)$ along the streamwise direction is defined as,

$\Delta H_{\text {nor }}=\frac{\Delta \dot{H}}{\dot{H}_{c, \text { in }}}=\frac{\int \rho u\left(h-h_{\text {in }}\right) d A}{\left[\int Y_{\mathrm{H}_{2}} \rho u h_{c} d A\right]_{(x=0)}}$

where $\Delta \dot{H}$ is the flux of total enthalpy change comparing to that at the inlet, $\dot{H}_{c, i n}$ is the flux of combustion enthalpy of $\mathrm{H}_{2}$ at the inlet, $h_{\text {in }}$ is the total enthalpy of the mixture at the inlet, $h_{c}$ is the combustion enthalpy per unit mass of $\mathrm{H}_{2}$. Profiles of $\Delta H_{n o r}$ along the streamwise direction for different combustor layouts at $v_{\text {in }}=40 \mathrm{~m} /$ sare shown in Fig. 8. The $\Delta H_{\text {nor }}$ declines along the streamwise direction as heat is transferred from gas to solid wall except for the "preheat zone" and the "bluff-body zone". The increase of $\Delta H_{n o r}$ in the "preheat zone" can be attributed to the heat recirculation effects [7], i.e., an indirect heat transfer from the burned gas to the fresh gas mixture via the heat conduction through the combustor wall. An additional sharp spike of $\Delta \mathrm{H}_{\text {nor }}$ appears in the "bluff-body zone" for the bluff body augmented combustors due to the rapid decreases of gas temperature in the boundary layers for the TRIANGLE and FIN combustors, as shown in Fig. 7b. The profiles of $\Delta H_{\text {nor }}$ in the upstream region of bluff body for the different combustors are almost overlapped, which reach the largest $\Delta H_{\text {nor }}$ of around 0.1 at the end of preheat zone. With the bluff body inserted, the decreasing rate of $\Delta H_{n o r}$ is slightly decreased in regions behind the bluff bodies, and eventually leads to smaller decrements in $\Delta H_{\text {nor }}$ at the outlet $(x=18 \mathrm{~mm})$. Accordingly, the heat loss ratios $\left(\mathrm{HLR}=-\Delta H_{\text {nor }}(x=18) * 100 \%\right)$

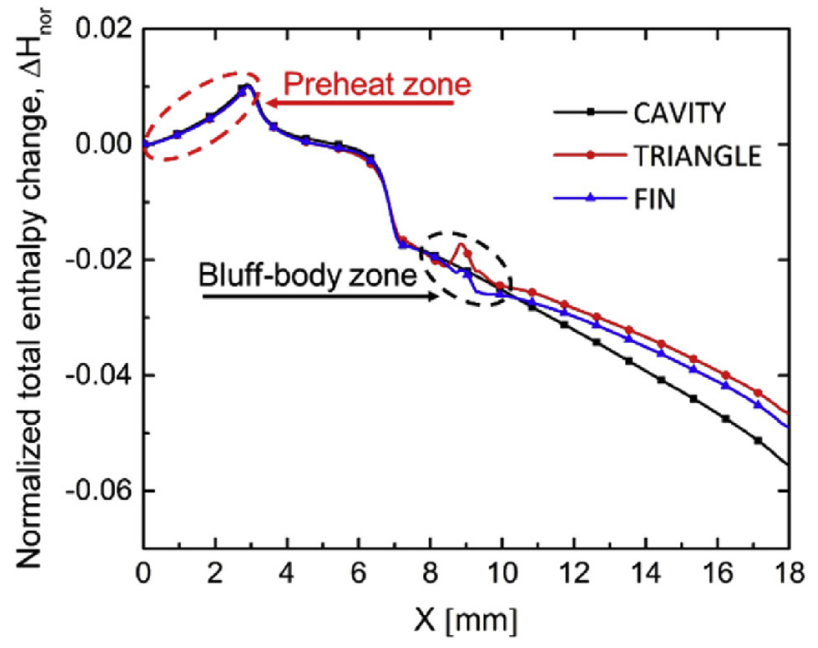

Fig. 8 - Normalized total enthalpy change profiles along the streamwise direction at $v_{\text {in }}=40 \mathrm{~m} / \mathrm{s}$.

of CAVITY, TRIANGLE and FIN are 5.56\%, $4.66 \%$ and $4.91 \%$ respectively, the largest reduction on HLR is only $0.8 \%$ observed in the TRIANGLE combustor for $v_{\text {in }}=40 \mathrm{~m} / \mathrm{s}$. Obviously, this marginal improvement on heat loss ratio is not the dominating mechanism in influencing the combustion efficiency.

\section{Flow field structures visualization}

Previous studies on bluff body stabilized flame in micro/meso scale combustors confirmed that the recirculation regions formed behind the bluff body can significantly enhance the flame stabilization due to the low-speed region and the accumulation of active radicals as well as heat [30,65]. Fig. 9 shows the contours of streamwise velocity for the three combustors at the inlet velocity of $40 \mathrm{~m} / \mathrm{s}$. It can be observed 
that a dual-vortexes flow structure is trapped in the cavity, which provides the low-speed zones for flame anchoring in the micro-cavity type combustors [41,42]. Besides, the velocity field behind the bluff bodies is quite different from the CAVITY combustor, where the small dual-vortexes are formed behind the bluff-bodies, and the main flow near the exit is accelerated to higher velocities.

To gain an insight into the effects of bluff bodies on the flow structure and interaction between flow and reaction. Mass fraction distributions of $\mathrm{OH}$ with the contour line of streamwise velocity in the zones behind the bluff bodies are shown in Fig. 10. The cases with inlet velocity of $24 \mathrm{~m} / \mathrm{s}$ and $40 \mathrm{~m} / \mathrm{s}$ were plotted separately to reveal the inlet velocity influences on different layouts. As shown in Fig. 10, the thin low-speed boundary layer accumulating $\mathrm{OH}$ radicals is formed in all combustors. Moreover, in the bluff body augmented combustors, the bluff bodies induce larger low-speed recirculation zones owing to the strong shear and boundary-layer separation effects. However, it is worth noting that in the TRIANGLE combustor no noticeable active radical accumulations and temperature rise in the recirculation zone can be observed, indicating that combustion cannot be sustained in the recirculation zone behind the triangulate bluff body. On the contrary, the wake zone of fins in the FIN combustor has trapped a large amount of high temperature products, which anchors the flame and consequently improves the flame stability and combustion efficiency. With the increase of inlet velocity, the velocity increased in the thin boundaries, which account for the prolonged flame and the weakened combustion efficiency. Meanwhile, the non-reactive recirculation
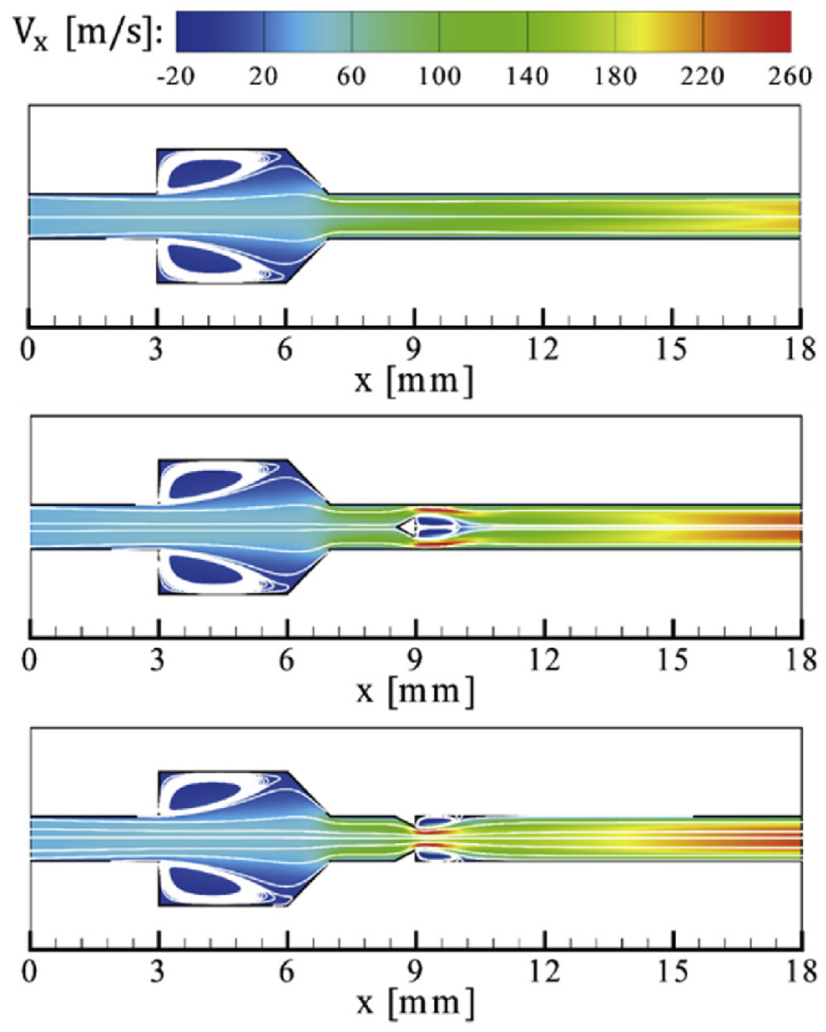

Fig. 9 - Contours of the streamwise velocity for different combustor layouts at $\mathrm{v}_{\text {in }}=40 \mathrm{~m} / \mathrm{s}$. zone in the TRIANGLE combustor is expanded as well, implying a negative effect on the improvement of combustion efficiency. Therefore, both favorable and adverse effects of bluff bodies exist in the FIN and TRIANGLE combustors.

\section{Reactants transport and reaction rate analysis}

Fig. 11 shows the distributions of mass fraction $\left(\mathrm{Y}_{\mathrm{H} 2}\right)$ and consumption rate of $\mathrm{H}_{2}\left(\mathrm{R}_{\mathrm{H} 2}\right)$ in the regions behind the bluff body of different combustors. It is found that the TRIANGLE combustor has the largest consumption rate, and the $\mathrm{R}_{\mathrm{H} 2}$ near the boundaries are much higher in the bluff body augmented combustors compared with the CAVITY combustor. Besides, comparing the distributions of $\mathrm{Y}_{\mathrm{H} 2}$ and $\mathrm{R}_{\mathrm{H} 2}$, a strong dependency can be observed between them. According to the previous study [68], $\mathrm{R}_{\mathrm{H} 2}$ is mainly controlled by the reactions:

$\mathrm{O}+\mathrm{H}_{2} \rightarrow \mathrm{H}+\mathrm{OH}$

$\mathrm{OH}+\mathrm{H}_{2} \rightarrow \mathrm{H}_{2} \mathrm{O}+\mathrm{H}$

Under fuel-lean conditions, the consumption rate of $\mathrm{H}_{2}$ is controlled by the concentration of $\mathrm{H}_{2}$ rather than that of $\mathrm{O}$ and $\mathrm{OH}$, which can explain the dependence between $\mathrm{Y}_{\mathrm{H} 2}$ and $\mathrm{R}_{\mathrm{H} 2}$ as shown in Fig. 11. Accordingly, the $\mathrm{H}_{2}$ transport from center to the boundary is essential for the consumption rate of $\mathrm{H}_{2}$.

To investigate the effects of the bluff bodies on hydrogen transportation, the hydrogen mass fraction overlaid with the contour lines of transverse hydrogen mass flux $\left(m_{c}^{\prime}\right)$ near bluff bodies is shown in Fig. 12, the $m_{c}^{\prime}$ is defined as,

$m_{\mathrm{c}}=\rho Y_{\mathrm{H}_{2}} \mathrm{v}$

where $v$ is the velocity component in the transverse direction. As shown in Fig. 12, the bluff body provides an order of magnitude enhancement of the $m_{c}$ near itself, which significantly improves the mixing between the high-temperature products and the cold reactants. The strong mass transportation of hydrogen from the combustor center regions to the lateral zones near the upper and lower sides of the bluff body in the TRIANGLE combustor contributes to the increase of $\mathrm{Y}_{\mathrm{H} 2}$ in the near-wall region as shown in Fig. 11. Consequently, a higher and wider consumption rate distribution is presented in the TRIANGLE combustor as depicted in Fig. 11, which contributes to the increase of combustion efficiency compared with the CAVITY combustor.

\section{Local Damköhler numbers}

The value of the Damköhler number is important to determine the combustion efficiency of micro combustors [1,69]. To evaluate the interactions between flow filed and the reaction of different layouts, the local Damköhler number, $D a_{L}$, is defined as

$D a_{L}=\frac{\text { reaction rate }}{\text { convective mass transfort rate }}=\frac{R_{\mathrm{H} 2} \tau}{\rho \mathrm{us}}$

where $\tau$ and $s$ are the unit volume and surface, respectively. The profiles of $D a_{L}$ in the transverse direction are depicted in Fig. 13 for various locations behind the bluff body at $v_{\text {in }}=40 \mathrm{~m} /$ $\mathrm{s}$. It can be found that the $\mathrm{D} a_{\mathrm{L}}$ have the maximum value at the 


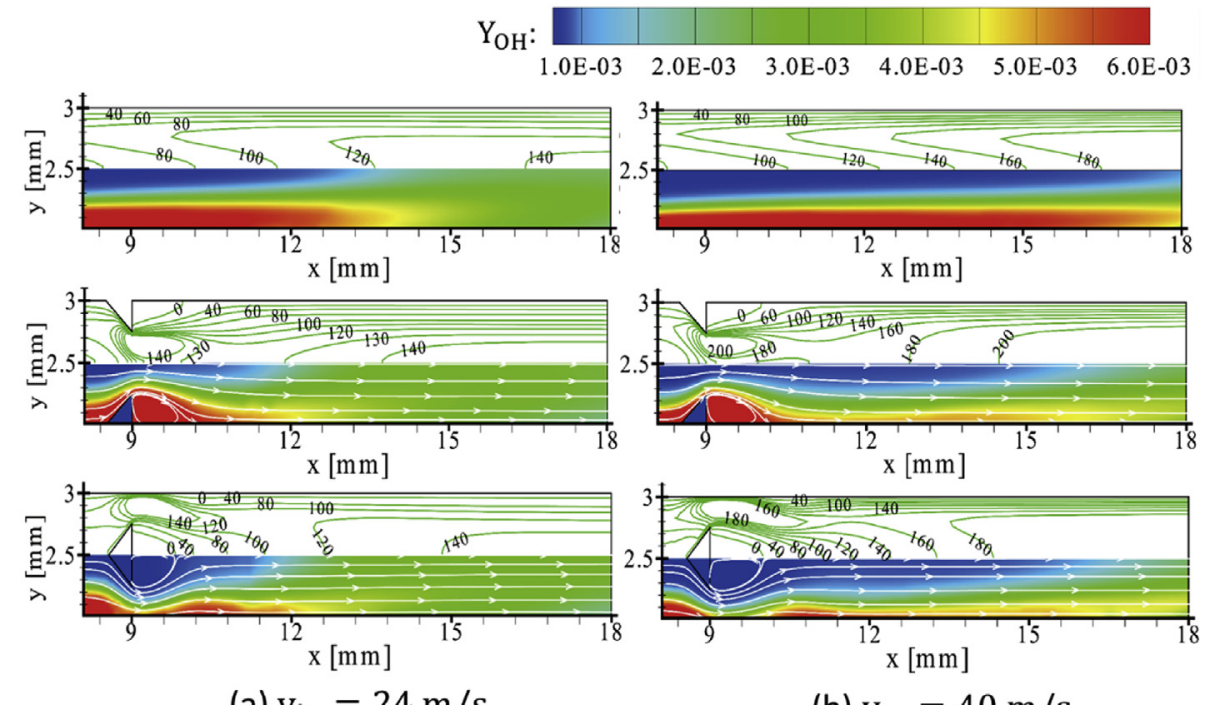

(a) $v_{\text {in }}=24 \mathrm{~m} / \mathrm{s}$

(b) $v_{\text {in }}=40 \mathrm{~m} / \mathrm{s}$

Fig. 10 - Contour line of streamwise velocity (up) and $\mathrm{OH}$ mass fraction distributions overlapped with streamlines (down) behind the bluff bodies at $(\mathrm{a}) v_{\text {in }}=24 \mathrm{~m} / \mathrm{s}$ and (b) $v_{\text {in }}=40 \mathrm{~m} / \mathrm{s}$
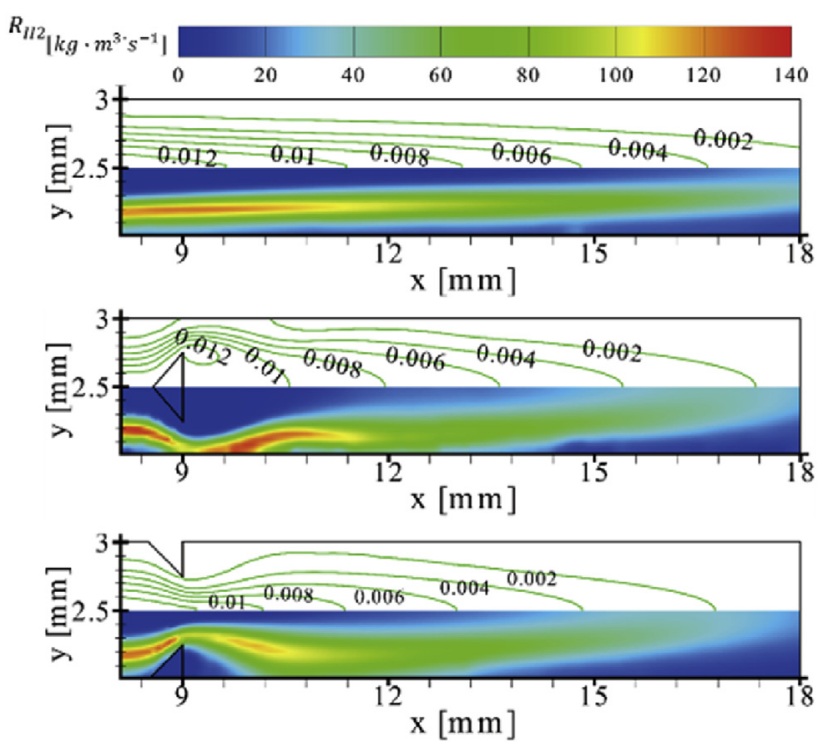

Fig. 11 - Contour lines of mass fraction (up) combined with contours of consumption rate (down) of $\mathrm{H}_{2}$ at $v_{\text {in }}=40 \mathrm{~m} / \mathrm{s}$.

boundary of the TRIANGLE and FIN combustors, whereas the peak value of $D a_{L}$ is appeared in the region between $\mathrm{y}=2.2$ and $\mathrm{y}=2.3 \mathrm{~mm}$ for the CAVITY combustor. Obviously, the overall $D a_{L}$ of bluff body augmented combustors is superior to the CAVITY combustor, and the FIN combustor has the largest $D a_{L}$. With the increase of $\mathrm{x}$ from 10 to 13 , the maximum of $D a_{L}$ of CAVITY, TRIANGLE and FIN decreases from 3.64, 5.57 and 11.85 to $2.15,1.92$ and 2.13 accordingly. The results show that the bluff body mainly facilitates the combustion near the wake of them. As depicted in Fig. 13a, in the wake region near the bluff body of the TRIANGLE combustor, the $D a_{L}$ is lower than that in the CAVITY combustor and close to zero except in the zone near the boundary, which leads to the decrease in the combustion efficiency as shown in Fig. 5. Recall the expanding

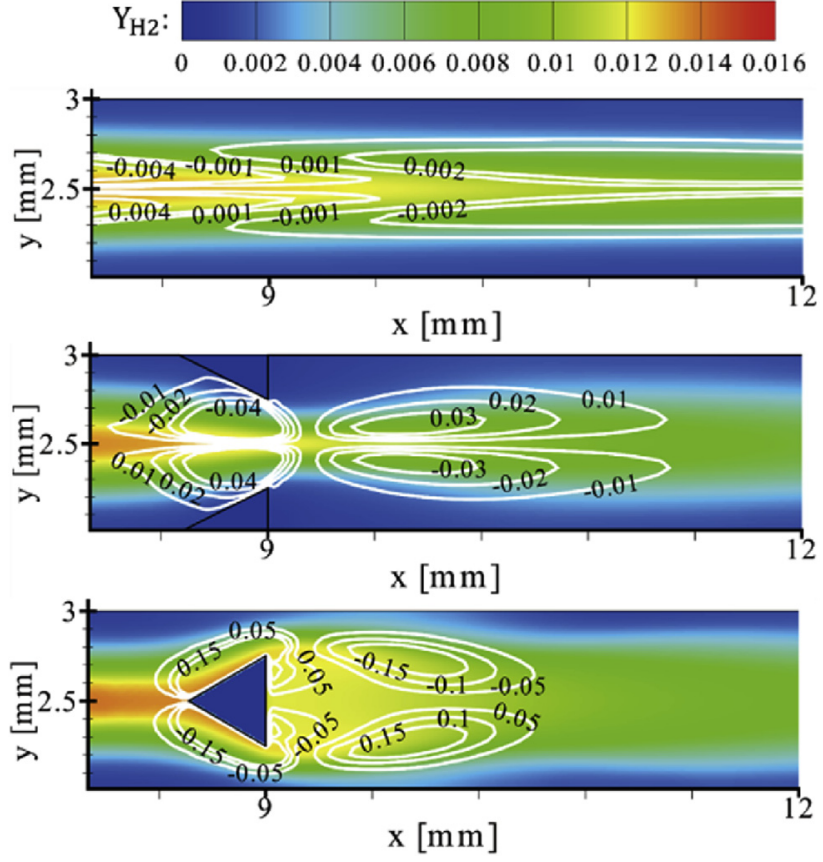

Fig. 12 - Contours of hydrogen mass fraction overlaid with iso-lines of transverse mass flux of hydrogen at $v_{\text {in }}=40 \mathrm{~m} / \mathrm{s}$.

of non-reacting wake region with the increased inlet velocity in Fig. 10, the reduction of $D a_{\mathrm{L}}$ in this region could be attributed to increase of inlet velocity, as a result of the improvement of the combustion efficiency for the TRIANGLE combustor.

The effects of the bluff body on combustion efficiency can be characterized by the value of $D a_{L}$. The low-speed reacting zones and enhanced transverse hydrogen transport induced by the fin structure produce a synergy effect to increase the $D a_{L}$, and remarkably improve the combustion efficiency of the 

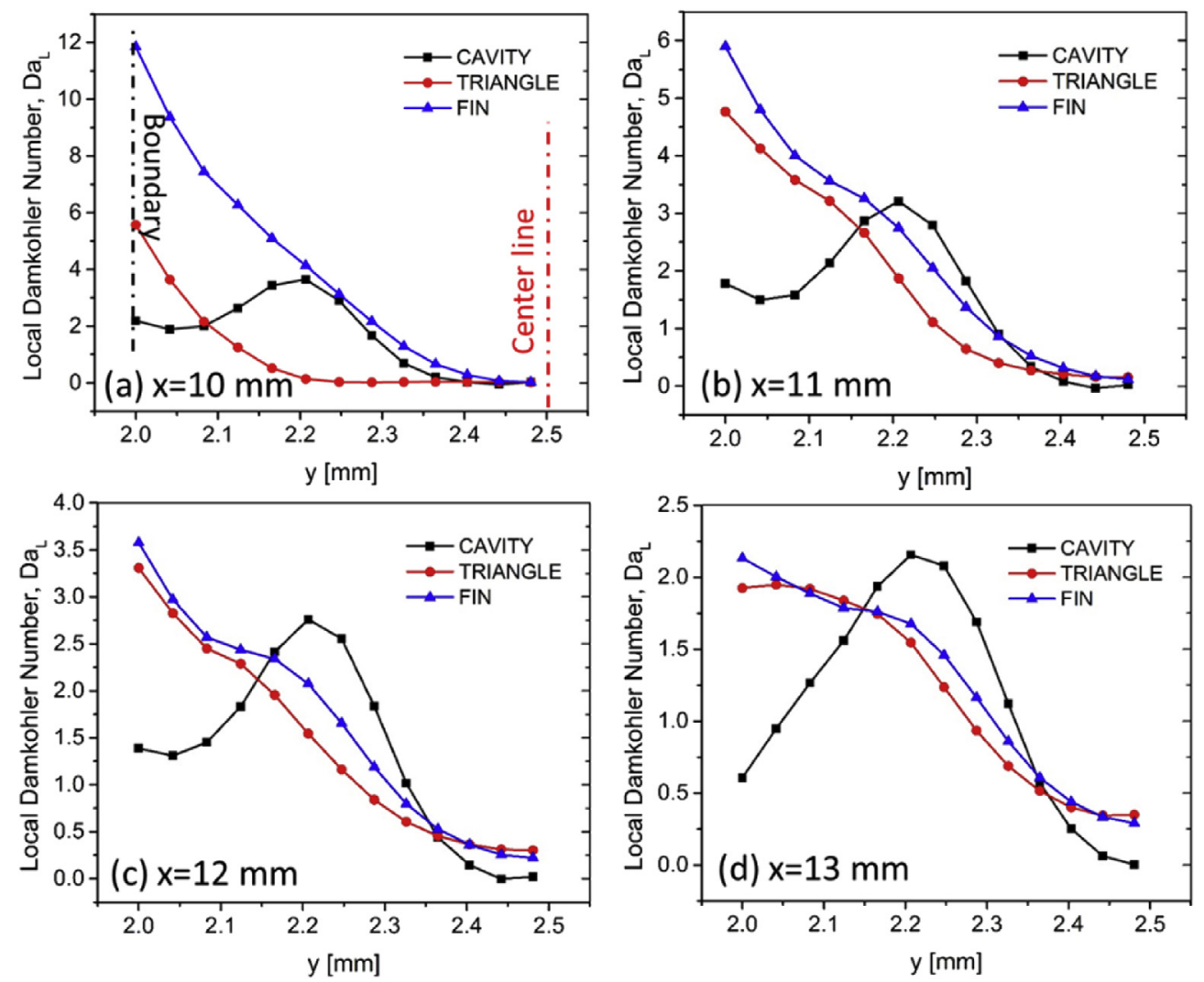

Fig. 13 - Profiles of $D a_{L}$ along transverse directions at various locations behind the bluff body at $v_{\text {in }}=40 \mathrm{~m} / \mathrm{s}$

FIN combustor consequently. For the TRIANGLE combustor, the contrary effects of central buff body on $D a_{L}$ in the nonreacting recirculation region and the near-boundary region diminish the increment of combustion efficiency, especially at higher inlet velocities.

\section{Conclusion}

In this study, the performances of the micro cavity combustor with and without the augmentation of the bluff bodies have been numerical studied with detailed $\mathrm{H}_{2}$ /air chemistry. Two types of bluff bodies, namely the triangulate and fin shaped configurations, are studied compared with the original cavity combustor under different inflow velocities. The effects of bluff body configurations in improving the flame stabilization and enhancing the combustion efficiency are revealed in terms of the thermal coupling, flow field analysis, reactant transportation, and chemical reactions. A local Damköhler number is defined to evaluate the coupling effects of fluid flow and chemical reactions. The main conclusions from the numerical analysis can be concluded as.

(1) The combustion efficiency declines accompanied by prolonged and splitting flame as the inlet velocity increases.

(2) The supplemented bluff body behind the cavity can significantly increase the combustion efficiency of the original micro cavity combustor. The fin-like bluff-body shows the optimal performance with the largest increase ratio of $10.1 \%$ for combustion efficiency.

(3) Heat transfer analysis demonstrates that the reduction of heat loss fraction is not the main contributor for the improvement of combustion efficiency in the bluff body augmented combustors.

(4) For the FIN combustor, the synergy effect of low-speed wake region accumulated with high temperature products and the enhanced transverse transport of hydrogen induced by the fin structure contribute to the significant improvements in combustion efficiency. For the TRIANGLE combustor, the intensified hydrogen consumption rate due to the intense mixing is receded by the large weakly reactive recirculation zone behind the bluff body.

(5) The local Damköhler number defined as the ratio of hydrogen consumption rate and convective mass transport rate is consistent with the variation of combustion efficiency along the streamwise direction, which provides an important indicator for the structure optimization of the micro-cavity combustors.

\section{Acknowledgements}

This work was carried out at the supercomputing system in the Supercomputing Center of University of Science and Technology of China. This work was supported by the 
National Key R\&D Program of China (No. 2018YFC0809500), Training Program of the Major Research Plan of National Natural Science Foundation of China (Grant No. 91641110).

\section{R E F E R E N C E S}

[1] Fernandez-Pello AC. Micropower generation using combustion: issues and approaches. Proc Combust Inst 2002;29:883-99.

[2] Ju YG, Maruta K. Microscale combustion: Technology development and fundamental research. Prog Energy Combust Sci 2011;37:669-715.

[3] Kaisare NS, Vlachos DG. A review on microcombustion: fundamentals, devices and applications. Prog Energy Combust Sci 2012;38:321-59.

[4] Milcarek RJ, Nakamura H, et al. Microcombustion for microtubular flame-assisted fuel cell power and heat cogeneration. J Power Sources 2019;413:191-7.

[5] Spalding DB. A theory of inflammability limits and flamequenching. Proc R Soc London, Ser A 1957;240:83-100.

[6] Daou J, Matalon M. Influence of conductive heat-losses on the propagation of premixed flames in channels. Combust Flame 2002;128:321-39.

[7] Ju YG, Xu B. Theoretical and experimental studies on mesoscale flame propagation and extinction. Proc Combust Inst 2005;30:2445-53.

[8] Aghalayam P, Bui PA, et al. The role of radical wall quenching in flame stability and wall heat flux: hydrogen-air mixtures. Combust Theor Model 1998;2:515-30.

[9] Raimondeau S, Norton D, et al. Modeling of hightemperature microburners. Proc Combust Inst 2002;29:901-7.

[10] Maruta K, Kataoka T, et al. Characteristics of combustion in a narrow channel with a temperature gradient. Proc Combust Inst 2005;30:2429-36.

[11] Kim KT, Dae HLB, et al. Effects of thermal and chemical surface-flame interaction on flame quenching. Combust Flame 2006;146:19-28.

[12] Kurdyumov VN, Jimenez C. Propagation of symmetric and non-symmetric premixed flames in narrow channels: influence of conductive heat-losses. Combust Flame 2014;161:927-36.

[13] Pan JF, Yang WM, et al. Micro combustion in sub-millimeter channels for novel modular thermophotovoltaic power generators. J Micromech Microeng 2010;20.

[14] Khandelwal B, Kumar S. Experimental investigations on flame stabilization behavior in a diverging micro channel with premixed methane-air mixtures. Appl Therm Eng 2010;30:2718-23.

[15] Kim NI, Kato S, et al. Flame stabilization and emission of small Swiss-roll combustors as heaters. Combust Flame 2005;141:229-40.

[16] Chou SK, Yang WM, et al. Porous media combustion for micro thermophotovoltaic system applications. Appl Energy 2010;87:2862-7.

[17] Li J, Wang YT, et al. Experimental study on standing wave regimes of premixed $\mathrm{H}$-2-air combustion in planar microcombustors partially filled with porous medium. Fuel 2016;167:98-105.

[18] Zuo W, J E, et al. Numerical investigations on different configurations of a four-channel meso-scale planar combustor fueled by hydrogen/air mixture. Energy Convers Manag 2018;160:1-13.

[19] Yan YF, Pan WL, et al. Numerical study of the geometrical parameters on $\mathrm{CH} 4$ /air premixed combustion in heat recirculation micro-combustor. Fuel 2015;159:45-51.
[20] Ronney PD. Analysis of non-adiabatic heat-recirculating combustors. Combust Flame 2003;135:421-39.

[21] Pizza G, Mantzaras J, et al. Suppression of combustion instabilities of premixed hydrogen/air flames in microchannels using heterogeneous reactions. Proc Combust Inst 2009;32:3051-8.

[22] Wierzbicki TA, Lee IC, et al. Combustion of propane with Pt and $\mathrm{Rh}$ catalysts in a meso-scale heat recirculating combustor. Appl Energy 2014;130:350-6.

[23] Chen JJ, Liu BF, et al. Computational fluid dynamics modeling of the combustion and emissions characteristics in hightemperature catalytic micro-combustors. Appl Therm Eng 2018;141:711-23.

[24] Maruta K, Takeda K, et al. Extinction limits of catalytic combustion in microchannels. Proc Combust Inst 2002;29:957-63.

[25] Yang WM, Chou SK, et al. Combustion in micro-cylindrical combustors with and without a backward facing step. Appl Therm Eng 2002;22:1777-87.

[26] Jiaqiang E, Zuo W, et al. Field synergy analysis of the microcylindrical combustor with a step. Appl Therm Eng 2016;93:83-9.

[27] Khandelwal B, Deshpande AA, et al. Experimental studies on flame stabilization in a three step rearward facing configuration based micro channel combustor. Appl Therm Eng 2013;58:363-8.

[28] Zarvandi J, Tabejamaat S, et al. Numerical study of the effects of heat transfer methods on $\mathrm{CH} 4 /(\mathrm{CH} 4+\mathrm{H}-2)$-AIR premixed flames in a micro-stepped tube. Energy 2012;44:396-409.

[29] Bazooyar B, Jomekian A, et al. The role of heat recirculation and flame stabilization in the formation of NOX in a thermophotovoltaic micro-combustor step wall. Int J Hydrogen Energy 2019;44:26012-27.

[30] Wan JL, Fan AW, et al. Experimental and numerica] investigation on combustion characteristics of premixed hydrogen/air flame in a micro-combustor with a bluff body Int J Hydrogen Energy 2012;37:19190-7.

[31] Wan JL, Fan AW, et al. Experimental investigation and numerical analysis on the blow-off limits of premixed CH4/ air flames in a mesoscale bluff-body combustor. Energy 2016;113:193-203.

[32] Fan AW, Wan JL, et al. The effect of the blockage ratio on the blow-off limit of a hydrogen/air flame in a planar microcombustor with a bluff body. Int J Hydrogen Energy 2013;38:11438-45.

[33] Bagheri G, Hosseini SE, et al. Effects of bluff body shape on the flame stability in premixed micro-combustion of hydrogen air mixture. Appl Therm Eng 2014;67:266-72.

[34] Niu JT, Ran JY, et al. Effects of trapezoidal bluff bodies on blow out limit of methane/air combustion in a microchannel. Appl Therm Eng 2016;95:454-61.

[35] Yilmaz H. Investigation of combustion and emission performance of a micro combustor: effects of bluff body insertion and oxygen enriched combustion conditions. Int J Hydrogen Energy 2019;44:25985-99.

[36] Amani E, Alizadeh P, et al. Micro-combustor performance enhancement by hydrogen addition in a combined bafflebluff configuration. Int J Hydrogen Energy 2018;43:8127-38.

[37] Yan Y, He Z, et al. Numerical study on premixed hydrogen/ air combustion characteristics in micro-combustor with slits on both sides of the bluff body. Int J Hydrogen Energy 2019;44:1998-2012.

[38] Yan Y, Xu F, et al. Influence of controllable slit width and angle of controllable flow on hydrogen/air premixed combustion characteristics in micro combustor with both sides-slitted bluff body. Int J Hydrogen Energy 2019;44:20482-92. 
[39] Su Y, Song JL, et al. Numerical investigation of a novel micro combustor with double-cavity for micro-thermophotovoltaic system. Energy Convers Manag 2015;106:173-80.

[40] Peng Q J E, et al. Investigation on the effects of front-cavity on flame location and thermal performance of a cylindrical micro combustor. Appl Therm Eng 2018;130:541-51.

[41] Wan JL, Yang W, et al. A numerical investigation on combustion characteristics of $\mathrm{H}$-2/air mixture in a microcombustor with wall cavities. Int J Hydrogen Energy 2014;39:8138-46.

[42] Li YH, Chen GB, et al. Enhancement of methane combustion in microchannels: effects of catalyst segmentation and cavities. Chem Eng J 2010;160:715-22.

[43] Wan JL, Fan AW, et al. The impact of channel gap distance on flame splitting limit of $\mathrm{H}$-2/air mixture in microchannels with wall cavities. Int J Hydrogen Energy 2014;39:11308-15.

[44] Wan JL, Fan AW, et al. Experimental investigation and numerical analysis on flame stabilization of $\mathrm{CH} 4 /$ air mixture in a mesoscale channel with wall cavities. Combust Flame 2015;162:1035-45.

[45] Wan JL, Fan AW, et al. A non-monotonic variation of blow-off limit of premixed CH4/air flames in mesoscale cavitycombustors with different thermal conductivities. Fuel 2015;159:1-6.

[46] Wan JL, Fan AW, et al. Effect of thermal conductivity of solid wall on combustion efficiency of a micro-combustor with cavities. Energy Convers Manag 2015;96:605-12.

[47] Yang W, Fan AW, et al. Effect of inlet temperature on combustion efficiency of lean H-2/air mixtures in a microcombustor with wall cavities. Appl Therm Eng 2016;107:837-43.

[48] Yang W, Fan AW, et al. Effect of reduced pressures on the combustion efficiency of lean $\mathrm{H}$-2/air flames in a micro cavity-combustor. Int J Hydrogen Energy 2016;41:15354-61.

[49] Yang W, Xiang Y, et al. Effect of the cavity depth on the combustion efficiency of lean H2/air flames in a micro combustor with dual cavities. Int J Hydrogen Energy 2017;42:14312-20.

[50] Yang W, Li L, et al. Effect of oxygen enrichment on combustion efficiency of lean H2/N2/O2 flames in a micro cavity-combustor. Chem Eng Process 2018;127:50-7.

[51] Fan A, Li L, et al. Comparison of combustion efficiency between micro combustors with single- and double-layered walls: a numerical study. Chem Eng Process - Process Intensification 2019;137:39-47.

[52] Li L, Yang W, et al. Effect of the cavity aft ramp angle on combustion efficiency of lean hydrogen/air flames in a micro cavity-combustor. Int J Hydrogen Energy 2019;44:5623-32.

[53] Kurdyumov VN, Pizza G, et al. Dynamics of premixed flames in a narrow channel with a step-wise wall temperature. Combust Flame 2009;156:2190-200.
[54] Pizza G, Frouzakis CE, et al. Dynamics of premixed hydrogen/ air flames in microchannels. Combust Flame 2008;152:433-50.

[55] Akram M, Kumar S. Experimental studies on dynamics of methane-air premixed flame in meso-scale diverging channels. Combust Flame 2011;158:915-24.

[56] Kuo CH, Ronney PD. Numerical modeling of non-adiabatic heat-recirculating combustors. Proc Combust Inst 2007;31:3277-84.

[57] Li L, Yang W, Fan A. Effect of the cavity aft ramp angle on combustion efficiency of lean hydrogen/air flames in a micro cavity-combustor. Int J Hydrogen Energy 2019;44:5623-5632.57.

[58] Fan A, Zhang H, et al. Numerical investigation on flame blow-off limit of a novel microscale Swiss-roll combustor with a bluff-body. Energy 2017;123:252-9.

[59] Norton DG, Vlachos DG. Combustion characteristics and flame stability at the microscale: a CFD study of premixed methane/air mixtures. Chem Eng Sci 2003;58:4871-82.

[60] Li J, Zhao Z, et al. An updated comprehensive kinetic model of hydrogen combustion. Int J Chem Kinet 2004;36:566-75.

[61] Kee RJ, Dixon-Lewis G, et al. A Fortran computer code package for the evaluation of gas-phase multicomponent transport properties. Sandia Natl Lab Rep SAND86-8246 1986;13:80401-1887.

[62] Kee RJ, Rupley FM, et al. The chemkin thermodynamic data base. Sandia Report SAND 1990:87.

[63] Brundage AL, Burl Donaldson A, et al. Thermocouple response in fires, part 1: considerations in flame temperature measurements by a thermocouple. J Fire Sci 2011;29:195-211.

[64] Chen Y-C, Bilger RW. Experimental investigation of threedimensional flame-front structure in premixed turbulent combustion: II. Lean hydrogen/air Bunsen flames. Combust Flame 2004;138:155-74.

[65] Kedia KS, Ghoniem AF. The anchoring mechanism of a bluffbody stabilized laminar premixed flame. Combust Flame 2014;161:2327-39.

[66] Brambilla A, Frouzakis CE, et al. Flame dynamics in lean premixed $\mathrm{CO} / \mathrm{H} 2 /$ air combustion in a mesoscale channel. Combust Flame 2014;161:1268-81.

[67] Yang W, Fan AW, et al. Effect of external surface emissivity on flame-splitting limit in a micro cavity-combustor. Appl Therm Eng 2015;83:8-15.

[68] Sanchez AL, Williams FA. Recent advances in understanding of flammability characteristics of hydrogen. Prog Energy Combust Sci 2014;41:1-55.

[69] Yang WJ, Deng C, et al. Experimental and numerical investigations of hydrogen-air premixed combustion in a converging-diverging micro tube. Int J Hydrogen Energy 2014;39:3469-76. 